\title{
Integrating engineering in $\mathrm{K}-12$ science education: spelling out the pedagogical, epistemological, and methodological arguments
}

\author{
Senay Purzer ${ }^{*}$ (D) and Jenny Patricia Quintana-Cifuentes
}

\begin{abstract}
This position paper is motivated by recent educational reform efforts that urge the integration of engineering in science education. We argue that it is plausible and beneficial to integrate engineering into formal K-12 science education. We illustrate how current literature, though often implicitly, discusses this integration from a pedagogical, epistemological, or methodological argumentative stance. From a pedagogical perspective, a historically dominant argument emphasizes how engineering helps make abstract science concepts more concrete. The epistemological argument is centered on how engineering is inherently interdisciplinary and hence its integrative role in support of scientific literacy and more broadly STEM literacy is natural. From a methodological perspective, arguments focus on the engineering design process, which is compatible with scientific inquiry and adaptable to answering different types of engineering questions. We call for the necessity of spelling out these arguments and call for common language as science and engineering educators form a research-base on the integration of science and engineering. We specifically provide and discuss specific terminology associated with four different models, each effectively used to integrate engineering into school science. We caution educators against a possible direction towards a convergence approach for a specific type of integrating engineering and science. Diversity in teaching models, more accurately represents the nature of engineering but also allows adaptations based on available school resources. Future synthesis can then examine student learning outcomes associated with different teaching models.
\end{abstract}

Keywords: Design, Engineering, Epistemology, Pedagogy, NGSS, Science

\section{Introduction}

In recent years, there has been an increasing interest in integrating engineering into kindergarten through high school (K-12) education. Engineering design is not a new concept in science education since it has been referred to as technological design in prior reform efforts such as the National Science Education Standards (National Research Council, 1996) and Benchmarks for Science Literacy (American Association for the Advancement of Science, 1994). Historically, the US state standards have paired engineering with scientific literacy or technological literacy, without an explicit focus on engineering as a core disciplinary idea or practice. Massachusetts was an

\footnotetext{
* Correspondence: purzer@purdue.edu

School of Engineering Education, Purdue University, 516 Northwestern Ave. Wang Hall 3500, West Lafayette, IN 47906, USA
}

exception and became a pioneer state in the United States after developing explicit K-12 engineering standards in 2001 and later in 2016 adopting the Next Generation Science Standards (Carr, Bennett IV, \& Strobel, 2012; Massachusetts Department of Education, 2001; Massachusetts Department of Elementary and Secondary Education, 2016). Moore and colleagues identified four states (Maine, Massachusetts, Minnesota, and Oregon) with explicit and comprehensive standards before the release of the Next Generation Science Standards (NGSS) (Moore, Tank, Glancy, \& Kersten, 2015). After the release of NGSS, other states followed through with varying levels of integration.

The National Academies have played an important role in shaping the academic discourse that positioned engineering in K-12 education. In 2009, the National Academy of Engineering published, Engineering in K-12 
education, summarizing ways engineering should be covered in formal K-12 education (National Academy of Engineering, 2009). Later, the Academy of Engineering published another report questioning if standards for K12 engineering education were needed (National Academy of Engineering, 2010). This latter report suggested an integrated approach for implementing engineering education in K-12 rather than employing a separate set of standards for engineering. The most influential report that had a significant impact on the integration of science and engineering in the United States has been $A$ Framework for Science Education, which promoted the importance of engineering practices and core ideas in science education (National Research Council, 2012) and guided the development of the Next Generation Science Standards (NGSS) (Achieve, 2013). What is particularly unique about NGSS, compared to previous reform efforts, is its focus on unifying disciplinary core ideas, practices, and cross-cutting concepts with its three-dimensional approach while promoting the integration of science and engineering (National Research Council, 2012).

Attributing to the novelties of NGSS, Moore and colleagues caution educators about potential challenges in the adaptation of NGSS given there are vast differences in ways engineering is covered in state standards (Moore et al., 2015). Teaching engineering, by effectively integrating it into science education is new to many educators as engineering education has not been part of their formal training (Watkins et al., 2018). This reform effort, with its ambitious framing, also necessitated an urgent need for improving curriculum, assessment, and teacher education in alignment with the new vision. To address this need, many researchers have focused on increasing teachers' familiarity with engineering and developing integrated curricula expanding across elementary (Capobianco \& Rupp, 2014; Moore, Tank, Gajdzik, et al., 2015; Museum of Science, 2019; Wendell \& Rogers, 2013) and secondary education (Cantrell, Pekcan, Itani, \& Velasquez-Bryant, 2006; Apedoe, Reynolds, Ellefson, \& Schunn, 2008; Daugherty \& Custer, 2012; Silk, Schunn, \& Cary, 2009; Peters-Burton \& Johnson, 2018). In this position paper, we draw attention to the differences in arguments that shape integration practices and elucidate related confusions.

Some of the early curricular efforts that integrate engineering and science were influenced by pedagogical models developed by learning scientists and science educators. Examples of these models include learning by design (Kolodner, 2002; Kolodner et al., 2003) and design-based science (Fortus, Dershimer, Krajcik, Marx, \& Mamlok-Naaman, 2004). Crismond (2001) was an exception in his approach to engineering design as a disciplinary core idea and with his theoretical framing shaped by the epistemology of engineering. Other models were designed based on the long-standing field of technology education with an emphasis on design methodology (International Technology Education Association, 2007). To sum, scholars have historically approached the integration of science and engineering from three different frames: as pedagogy, as epistemology, and as methodology. These differences are often not recognized nor stated explicitly, yet they have profound impact on shaping classroom practices.

The success of new reform efforts lies in our ability to predict and prepare for variations in how reform ideas are implemented in the classroom and how beginner practices are sculpted into informed practices. Interestingly, a similar variation has occurred in science education as part of the inquiry-based learning movement (Chinn \& Malhotra, 2002). In their seminal work, Chinn and Malhotra (2002) discuss ways in which inquiry is viewed as a pedagogy, a scientific practice, and a mode for students' scientific investigations in the classroom. According to Chinn and Mathotra, many scientific inquiry tasks secondary school students engage in do not reflect the core attributes of authentic scientific inquiry and even conflict with the epistemology of authentic science. This discrepancy is attributed to the misinterpretations of inquiry as a hands-on pedagogy rather than a disciplinary practice.

The conceptualization of integrating science and engineering shapes how teacher educators justify the necessity, appropriateness, and value of the integration, how teachers approach their practice, and eventually what students gain from such an interdisciplinary integration. These distinctions and clarifications are also vital for the potency of research and its ability to improve teaching and learning. One of the main purposes of this article is to clarify the language and the positionality of researchers so research can be better framed, categorized, and synthesized. We need to spell out the underlying framing positioned in arguments for integration and call for common language as science and engineering educators form a research-base which facilitates the integration of science and engineering. More importantly, the approaches to integrating engineering in science education must recognize the pedagogical power, epistemological pluralism, and methodological flexibility of engineering design. We call for the necessity of recognizing divergence in teaching models in alignment with the nature of engineering. We also argue against a possible tendency for a convergence approach towards a specific model of integrating engineering and science and offer ideas to guide curriculum, teacher professional development, and research.

\section{Why do the reform efforts promote integration of engineering in science education?}

We invite researchers and educators to ask why it is plausible to integrate engineering into formal K-12 
science education. What are the purposes, reasons and propellers behind the reform effort calling for such integration? What tenets in engineering education capture the importance of disciplinary integration? Is engineering design a specific teaching method (pedagogy), a disciplinary core idea (epistemology), or a disciplinary practice (methodology)?

When answering these questions, it is inevitable to get into a discussion of the similarities and differences of these disciplines. Philosophers of science, engineering and technology have deliberated over the differences between science and engineering. As Radder (2009) concludes, any attempt to define and differentiate science and engineering prove to be debatable and that science and engineering exhibit patterns of similarities and differences. While engineering is typically defined as the creation of objects and systems for social use, the introduction of engineering sciences further complicates the distinction between engineering and science. In engineering sciences, the scientific knowledge generated is typically tied to artificial objects (artifacts, systems, or processes) as opposed to natural objects. For example, the research on engineering thermodynamics can be trailed back to the invention of the steam engine (Mitchan \& Schatzberg, 2009). Take another example, the following three questions inspired by examples by Kroes (2009a, 2009b):

a) What is the structure of the metacarpal bone?

b) What material properties increase the maximum load that a proposed prosthetic design can bear?

c) How do we design a prosthetic hand that satisfies a list of technical and user requirements (e.g., for children)?

The first one is a scientific research question; the second one is an engineering research question (engineering science), and the last one is an engineering design question. If we set aside the engineering science question and focus on the two distinct questions (a and c), three aspects of engineering design differentiate it from scientific research (Lewis, 2006; Radder, 2009):

- Purpose: Science aims for explanatory knowledge and engineering aims for socially useful, pragmatic solutions designed to meet human needs.

- Context: The nature of science demands explanations that are context-free and generalizable, while engineering demands context-dependent but transferable knowledge.

- Trade-offs: Associated with its contextualized nature, engineering aims to achieve design requirements (such as effectiveness, efficiency, feasibility, safety, and sustainability) under constraints, and hence requires trade-offs. Science demands decontextualized and idealized conditions.

While there are clear epistemological differences between science and engineering, distinguishing the practices of science and engineering as starkly different can be problematic. That is because when the domainindependent aspects of science and engineering are defined, both science and engineering can be argued to have common characteristics. Both disciplines share the following common characteristics:

- employ analytic as well as synthetic methods and require inductive, deductive, and abductive reasoning (Kroes, 2009b),

- practice questioning, observing, and experimenting as essential activities (Dyer, Gregersen, \& Christensen, 2008),

- depend on evaluative judgement made by people whether by convincing the scientific community of the quality of scientific arguments or by satisfying clients or stakeholders of the design decisions,

- strive to make evidence-based arguments (in order to support scientific claims or engineering design decisions).

The meaningful differences between science and engineering are not in terms of their practices (e.g., asking questions, observing, experimenting) but rather in terms of their purpose and motives. Interestingly, $A$ Framework for K-12 Science Education (National Research Council, 2012) and NGSS (Achieve, 2013) emphasizes the differences between the practices of science and engineering in only two of its eight practices. For example, as illustrated in Table 1, the practice of planning investigations, conducting tests and experiments is common to both science and engineering disciplines. Both disciplines carry out investigations to understand the causal relationships between variables (Crismond \& Adams, 2012). Carrying out investigation in science is done to test how empirical data compare to hypothesized results (Lewis, 2006). Alternatively, in engineering, predictions are based on possible behaviors of prototypes and testing is employed to try out these predictions in order to determine optimization levels of prototypes. The use of more precise terminology such as "scientific research and scientific explanations" and "engineering design/ research and engineering solutions/answers" can help clarify the relative purposes and practices.

In sum, the design process involves asking questions, making observations, and collecting evidence, similar to scientific inquiry. However, the contextualized problem, the design constraints and trade-offs, 
Table 1 Science and engineering practices outlined in NGSS (Achieve, 2013)

\begin{tabular}{|c|c|}
\hline Practices that are specified for science vs engineering in NGSS & Practices that are not differentiated in NGSS \\
\hline $\begin{array}{l}\text { - Asking [scientific research] questions (for science) and defining } \\
\text { [engineering design] problems (for engineering) } \\
\text { - Constructing [scientific] explanations (for science) and designing } \\
\text { [engineering] solutions (for engineering) }\end{array}$ & $\begin{array}{l}\text { - Developing and using models } \\
\text { - Planning and carrying out investigations } \\
\text { - Analyzing and interpreting data } \\
\text { - Using mathematics and computational } \\
\text { thinking } \\
\text { - Engaging in argument from evidence } \\
\text { - Obtaining, evaluating, and communicating } \\
\text { information }\end{array}$ \\
\hline
\end{tabular}

The text in brackets are added by the authors for clarification and emphasis

and the need for a practical solution influence how engineers utilize the process (where they start, what kind of questions they ask).

\section{Pedagogical power, epistemological pluralism, and methodological flexibility of engineering}

Three types of arguments have historically shaped the infusion of engineering into K-12 education: the pedagogical, the epistemological, and the methodological. One reason for the variety in arguments is that research communities have adopted different approaches to integrating engineering in K-12 education. In science education, the popular one has been the pedagogical argument. For engineering and technology education, the epistemological and methodological arguments respectively, tend to be prevalent. The supporting and counter arguments are summarized in Table 2.

The pedagogical argument cultivates the pedagogical power of utilizing engineering in science education. The epistemological argument values the nature of engineering and its interdisciplinary nature. The methodological argument highlights engineering practices as transferable skills necessary for all students. As summarized through the counter arguments in Table 2, curriculum and instruction may have different potencies and may result in different drawbacks depending on the arguments they are built on. For example, if engineering is viewed as pedagogy, components associated with the nature of engineering and informed design practices may be left out. If a methodological perspective is adopted in designing curricula, there might be over-emphasis on the design process and elements of scientific core ideas may be overlooked. The following sections detail each of these arguments.

\section{The pedagogical argument}

In the early 1900s, research studies in the learning sciences have started to emerge by using design as pedagogy. The underlying idea in these models is that scientific concepts are abstract, and integrating engineering in science classes can show students the applicability of scientific concepts in pragmatic ways pertaining to the society they live in and the different spaces they interact with. Even when we think of the simplest science activities that we implement to support conceptual understanding, essentially many are built on engineering foundations. For example, a common science activity, lighting a bulb with a battery and a wire by building a circuit, is in fact an engineering geared activity. The integration models that are built on pedagogical arguments are elaborate in their scaffolding as they aim to enhance student learning in disciplinary core ideas of physical, life, and earth sciences.

The aim of the pedagogical models is to promote deeper understanding of disciplinary core ideas in science, these models have taken different names such as designbased science (Fortus et al., 2004), design-based learning (Apedoe \& Schunn, 2013), and learning by design (Kolodner et al., 2003). In these arguments, design is utilized as a pedagogy to teach disciplinary concepts in science. Educators' use of design as a pedagogical argument can be understood in parallel to inquiry-based learning, as illustrated in Fortus and colleagues' study, which presents their design-based learning model as an

Table 2 Comparing arguments for integrating science and engineering

\begin{tabular}{llll}
\hline & Pedagogical argument & Epistemological argument & Methodological argument \\
\hline $\begin{array}{l}\text { Supporting } \\
\text { Arguments }\end{array}$ & $\begin{array}{l}\text { Pedagogical Power: Engineering helps } \\
\text { make abstract science concepts } \\
\text { concrete. Engineering is the application } \\
\text { of science. }\end{array}$ & $\begin{array}{l}\text { Epistemological Pluralism: Engineering is } \\
\text { inherently interdisciplinary; the integration } \\
\text { of science and engineering (as well as other } \\
\text { disciplines) is a natural part of problem setting. }\end{array}$ & $\begin{array}{l}\text { Methodological Flexibility: Students need } \\
\text { to develop abilities to solve problems, } \\
\text { and engineering design provides strategies } \\
\text { to do so. }\end{array}$ \\
$\begin{array}{llll}\text { Counter } \\
\text { Arguments }\end{array}$ & $\begin{array}{l}\text { "Engineering" as a disciplinary core idea } \\
\text { and a disciplinary practice may be left } \\
\text { out. }\end{array}$ & $\begin{array}{l}\text { Scientific and mathematical concepts can } \\
\text { differ based on the solutions students pursue. } \\
\text { Requires comfort in managing complexity. }\end{array}$ & $\begin{array}{l}\text { Core ideas in science and mathematics } \\
\text { concepts may be left out due to a focus } \\
\text { on process. }\end{array}$ \\
\hline
\end{tabular}


alternative to scripted or inquiry-based learning models (Fortus et al., 2004).

Given the pedagogical focus on these arguments, the dimensions of engineering as a disciplinary core idea and a disciplinary practice might be overlooked, with a focus to promote disciplinary core ideas in science. Reimagining the pedagogical models, with a lens that reflects the epistemology and methodology of engineering, presents an opportunity to highlight the reciprocal relationships between science and engineering.

\section{The epistemological argument}

The epistemological argument reflects how engineering in its interdisciplinary nature requires literacies in a range of disciplines. Engineering is inherently an interdisciplinary field, hence, engineering naturally integrates science in its arguments and practices (See Fig. 1). As Cajas (2001) has argued, engineering occurs at the intersection of multiple disciplines, and its processes and technological artifacts are important for the general public. In addition, engineering problems are diverse requiring processes for optimization, experimentation, and innovation (See Fig. 1). Some engineering questions resemble science questions (experimentation in engineering sciences); some value prototyping and testing (design-build-test); others have heavier emphasis on analysis and mathematics (optimization), and the remaining ones are more complex with their framing of technological, social, and economic factors (innovation).
Educational researchers, who study integration with a focus on the epistemological nature of engineering, frequently highlight that engineering involves working with constraints that can be economic, societal, legal, or environmental, and that design values the satisfaction of end users (Cunningham \& Kelly, 2017; Figueiredo, 2008; Svarovsky, 2011). If engineering activities do not meaningfully integrate science or mathematics content, they no longer fully represent engineering (Purzer, Moore, Baker, \& Berland, 2014).

Engineering carries elements of science and mathematics but also arts and humanities (Radcliffe, 2015). One reflection of the integrative nature of engineering is witnessed in typical undergraduate engineering curricula which start with fundamentals in science and mathematics in the first and second years of post-secondary education and disciplinary specialties in engineering during the third and fourth years of the program. We might also question the role of engineering in mathematics education, especially in its K-12 standards. There are, in fact, models for integrating engineering in mathematics through mathematical modeling (Hamilton, Lesh, Lester, \& Brilleslyper, 2008). However, perhaps the applied nature of mathematics in engineering is not considered as comprehensive enough for a wide-spread integration (Czerniak, Weber Jr, Sandmann, \& Ahern, 1999). Still, the integration of mathematics is evident in the Next Generation Science Standards, with footnote connections to the Math Core Standards. In addition,

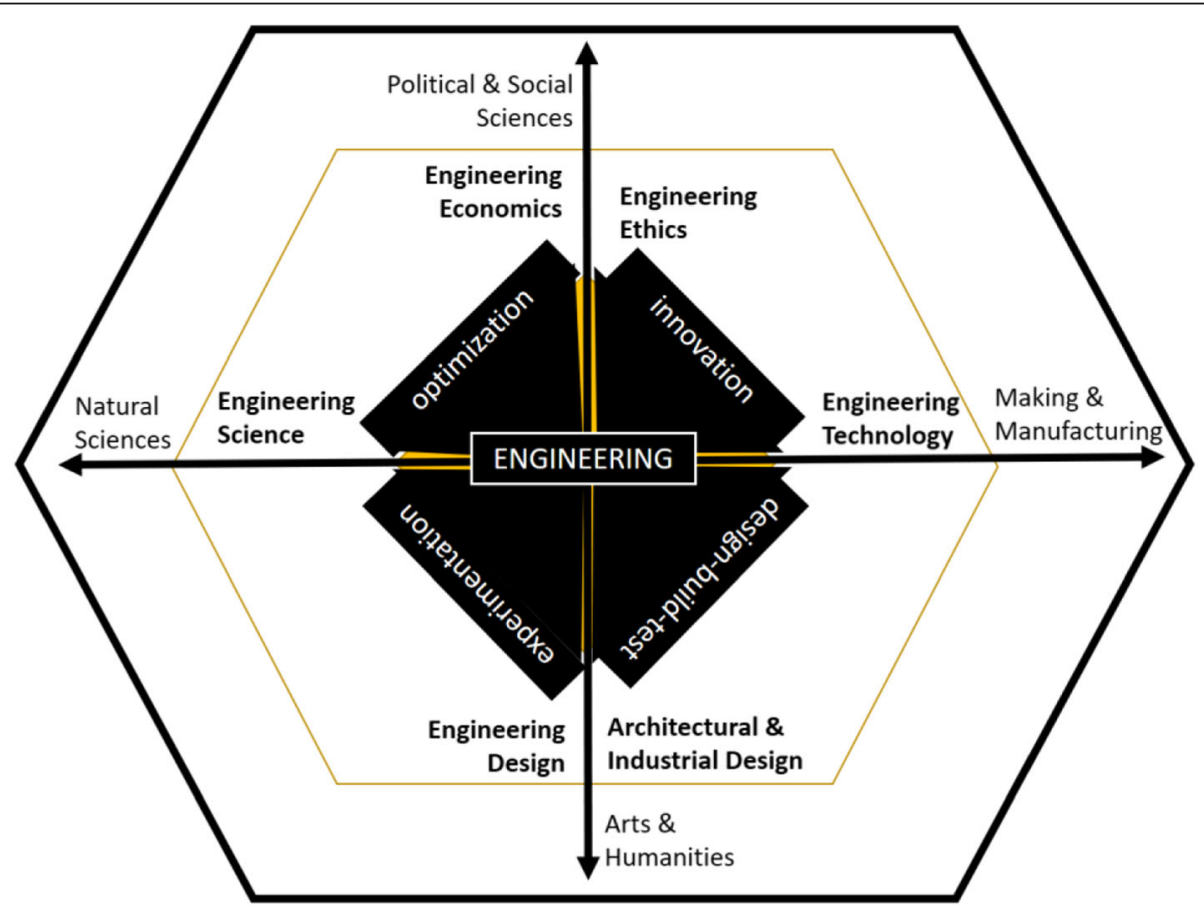

Fig. 1 Technical and social dimensions of engineering (adopted from Dixon, 1966) 
some researchers label the integration more broadly as integrated STEM, which recognizes mathematics and technology as part of the integration (Pang \& Good, 2000; Berland, 2013; Roehrig, Moore, Wang, \& Park, 2012).

While engineering naturally supports the integration of its core ideas in science and other disciplinary subjects of K-12 education, managing such integration especially in disciplinary-isolated grade-levels and standards might be challenging. In secondary education, interdisciplinary teacher collaboration would be necessary and found to be effective (Goldstein, Loy, \& Purzer, 2017). At the elementary levels, such integration is easier but teacher professional development would need to make the epistemology of engineering evident, not as an alternative to science, but in harmony with science. Teaching epistemologicallyrealistic engineering requires comfort with complexity and agility in effectively scaffolding different design solutions developed by the students.

\section{The methodological argument}

The methodological argument focuses on design as a disciplinary practice of engineering and hence as a reflection of the disciplinary practices of the field. Historically technology, engineering, and design were considered parts of scientific literacy. For example, Cajas asked, "What exactly is the role of understanding technology in science education? What specific technological ideas and skills are fundamental for science literacy?" (Cajas, 2001, p. 716). Today, scientific literacy and technological literacy are distinguished (Sneider \& Purzer, 2014). Technological literacy is then defined as what all students should know about engineering concepts and practices to effectively participate in a technically-rich world, where technology is the designed world and engineering is the process of designing this world (National Academy of Engineering, 2009).

When studying students' understanding of the design practices, researchers have typically used think-aloud protocols and measured the amount of time students spent at each stage of design as compared to experts (Alemdar, Lingle, Wind, \& Moore, 2017; Hsu, Cardella, \& Purzer, 2012; Mentzer, Becker, \& Sutton, 2015). Collectively, the studies on student design processes argue that problem scoping and information gathering are major challenges for students (Crismond \& Adams, 2012). Hence, studies of curriculum and classroom environment (Mathis, Siverling, Glancy, \& Moore, 2017; Nathan, Atwood, Prevost, Phelps, \& Tran, 2011) in association with the amount of time spent in each aspect of the design process is essential (Mentzer et al., 2015). Here, a critical learning outcome is students' understanding of informed design practices and abilities to become better designers over time. Yet, except for a few (e.g., Hsu et al., 2012), a limited number of studies tackle teachers' and students' understanding of design as a disciplinary practice.

The arguments made for integration from a methodological stance also highlight the importance of developing students as confident problem-solvers and decisionmakers. These can resemble discourse about scientific and technological literacies that are more commonly seen in American Association for the Advancement of Science (AAAS) publications as well as in NAEP and PISA (American Association for the Advancement of Science, 1994; National Assessment of Educational Progress, 2014; OECD, 2014). For example, the Programme for International Student Assessment (PISA) added 'creative problem solving' and later 'collaborative problem solving' to its suite of assessments in addition to assessments of scientific literacy, mathematics, and reading (OECD, 2014, 2017). The methodological argument highlights the importance of solving complex problems that require trade-off decisions, and students need to develop skills on how to make such decisions (Purzer, Goldstein, Adams, Xie, \& Nourian, 2015).

When instructional arguments are solely based on methodology, educators can face the problem of defining design and the designed artifacts too broadly, beyond the disciplinary scope of engineering. This could result in misalignment with NGSS, where core ideas in science and mathematics concepts may be left out due to a focus on process.

In summary, the approaches to integrating engineering in science education must recognize the pedagogical power, epistemological pluralism, and methodological flexibility of engineering. Moreover, a pluralist approach is necessary not only because it depicts the different facets of engineering as a field, but it is necessary from a pedagogical perspective because the use of different models supports different learning outcomes (Goldstein, Omar, Purzer, \& Adams, 2018). The intersectionality of the approaches is important to recognize as each approach carries strengths and limitations with respect to the contextualized integration of engineering in $\mathrm{K}-12$ education.

From a practical perspective, the diversity of approaches can equalize the imbalance of school resources while still promoting important learning experiences and learning outcomes. For example, Goldstein and colleagues compared two different design projects (one with an interdisciplinary project involving a real client and another with a fictional client with a short project). Their analysis showed that the former group had higher gains than the latter group while both groups had significant learning gains in terms of their understanding of science concepts. When time and resources were considered, the investment in time in relationship to learning gains appeared to have balanced out. 
The pedagogical power of engineering in $\mathrm{K}-12$ education is well-examined in the literature. However, much work is necessary for examining engineering's role in $\mathrm{K}$ 12 education from epistemological and methodological stances. Studying engineering practices in the classroom would require adopting a pluralistic approach and multiple protocols. In 2002, an influential study in science education examined types of teaching materials and curricula and how closely they reflected real science experiments (Chinn \& Malhotra, 2002). In comparison to Chinn and Malhotra's approach, a single protocol evaluating authenticity would be misleading when examining engineering. The variation in approaches used in K-12 classrooms might be due to an unfamiliarity with engineering and misinterpretations of its practices. However, it is also possible that the variations might be a reflection of engineering as a multi-facetted discipline (Purzer, 2018; Purzer \& Quintana-Cifuentes, 2019). In this paper, we outline the variations in alignment with the nature of engineering.

An exposure to a single approach for integration could potentially result in misinterpretations of the nature of engineering and cause confusion in defining integrated curriculum models, in how teachers conceptualize this integration, and how the body of research evolves and guides future directions. If not delineated, these differences could create misunderstandings about the purpose of engineering design and the targeted learning outcomes. Hence, we clarify these differences as we demarcate between pedagogical, epistemological, and methodological arguments, as well as we advocate that researchers state their perspectives more explicitly (See Table 2).

\section{Pedagogical models reflecting epistemological pluralism and methodological flexibility of engineering}

In earlier sections, we differentiated between pedagogical, epistemological, and methodological approaches to integration and argued for the need to recognize these variations and called for a divergent approach to curricular models. While diverse, the integration models have to reflect the nature of engineering but also be transferable to classroom practices. In Table 3, we present several divergent models that emerged from a synthesis of articles published in NSTA's teacher journals (Purzer, 2018; Purzer \& Quintana-Cifuentes, 2019). These models can be categorized under two main headings in alignment with the nature of engineering: new design and re-design in engineering. New design refers to addressing a set of design requirements with a designed object (referring to an artifact, a system, or a process). Re-design refers to refining a sub-optimal object. This classification captures engineering elements of divergence and convergence, synthesis and analysis, induction and deduction.

The integration models presented in Table 3 showcase the multi-faceted nature of engineering, with dimensions resembling pragmatic innovation (new design) and scientific approach (re-design). The different emphasis areas in engineering practices required to solve different types of problems would likely have implications on the learning outcomes of the students.

\section{User-centered engineering design model}

This model adopts the user-centered and contextualized nature of design. Students are typically presented with a problem from a real or simulated client (Ewalt, Dortch, \& Russell, 2015; Karahan, Guzey, \& Moore, 2014). Problem scoping is essential in understanding the needs, defining criteria and constraints, along with articulating a clear problem statement. Novel engineering, an instructional model developed by researchers at Tufts University, is a great example of user-centered engineering design implemented in elementary classrooms. Novel Engineering promotes problem scoping by engaging students in determining the needs of characters in books and novels, understanding and articulating the problem context and developing design criteria and constraints.

Table 3 Engineering-science integration models

\begin{tabular}{|c|c|c|c|c|}
\hline & \multicolumn{2}{|l|}{ New design in engineering } & \multicolumn{2}{|l|}{ Re-design in engineering } \\
\hline & $\begin{array}{l}\text { User-centered engineering } \\
\text { design }\end{array}$ & $\begin{array}{l}\text { Design-build-test } \\
\text { (DBT) }\end{array}$ & $\begin{array}{l}\text { Engineering science } \\
\text { experimentation }\end{array}$ & $\begin{array}{l}\text { Design } \\
\text { optimization }\end{array}$ \\
\hline Heavier on synthesis & $\checkmark$ & $\checkmark$ & & \\
\hline Contextualized (requires problem scoping) & $\checkmark$ & $\checkmark$ & & \\
\hline Heavier on analysis & & & $\checkmark$ & $\checkmark$ \\
\hline Scientific (requires experiments) & & & $\checkmark$ & $\checkmark$ \\
\hline Requires new design, that is new to the context & $\checkmark$ & $\checkmark$ & & \\
\hline $\begin{array}{l}\text { Process starts with a sub-optimal artifact, } \\
\text { process, or system }\end{array}$ & & & $\checkmark$ & $\checkmark$ \\
\hline Number and type of criteria & Multiple, complex criteria & $\begin{array}{l}\text { Multiple, simple } \\
\text { criteria }\end{array}$ & Typically single criterion & $\begin{array}{l}\text { Typically two } \\
\text { criteria }\end{array}$ \\
\hline
\end{tabular}


There are also integrated STEM units that emphasize clients and users (Mathis, Siverling, Glancy \& Moore, 2017; Cook, Bush, \& Cox, 2015) and engage students with stakeholders. In a middle school design project, Goldstein et al. (2017) have collaborated with a local homebuilder aiming to design a sustainable neighborhood. In this study, researchers found increased improvement in students' ability to apply science concepts to design scenarios (Chao et al., 2017; Goldstein et al., 2018).

\section{Design-build-test (DBT) model}

Design-build-test projects, when done in engineering, carries the purpose of testing a prototype and establishing proof of a principle. Such testing can take many forms such as verification of functional models (prototypes) and simulations with virtual models (Batliner, Boës, Heinis, \& Meboldt, 2018). When used in engineering during post-secondary education, this model provides engineering students the opportunity to apply and validate concepts and principles from their analytic studies (American Institute of Aeronautics and Astronautics, 2019). In K-12 education, DBT is the most common approach used in the classroom (Purzer \& QuintanaCifuentes, 2019). In this model, students are provided with specific design requirements while constraints are typically tied to the activity such as available materials and time. Researchers caution against two possible directions that can weaken DBT model's epistemological connection to engineering. These activities can unintentionally turn into arts and crafts activities (Purzer et al., 2014). In addition, DBT emphasizes building and construction activities, which take much of class time. Yet, testing and reflection that follow construction, are essential for good design and deep learning (Chao et al., 2017). While artifacts play an important role in engineering design, built prototypes allow testing and data gathering so decisions can be made.

\section{Engineering science experimentation model}

This model along with its approach are the closest to scientific research because the engineering experimentation model values controlled experiments. In this model, a prototype is built following a scripted procedure. In building a prototype for testing, one variable is manipulated to evaluate its impact on an outcome (Hoffmann, 2013). Then, through controlled experiments and analyses, the most effective outcome (e.g., material or shape) is identified based on a specific design criterion. For example, in a lesson on tissue engineering, students followed a protocol to build columns made from alginate gel (Ballyns, Doran, Archer, \& Bonassar, 2011). They test their specimens using compression tests. The project's goal was to produce the strongest material. The engineering experimentation model reflects the type of research engineers conduct at universities or industrial research labs; hence, this aspect of engineering is similar to scientific practice. The engineering experimentation model is among the least commonly used in the US education system (Purzer \& Quintana-Cifuentes, 2019) despite the fact that the model is most closely aligned with scientific inquiry with its focus on controlled, systematic experimentation processes.

\section{Design optimization model}

This model focuses on improving an existing system or a product that functions with a sub-optimal performance. This model aims to improve an existing system or protoype within competing criteria or constraints (Dasgupta, Sanzenbacher, Siegel, Mcbeath, \& Moher, 2017). Hence, students are engaged in the analysis of a suboptimal system and the diagnosis of its problems. The practice requires design trade-offs and aims to optimize the performance of an artifact or a system with a revised one. Xie, Schimpf, Chao, Nourian, and Massicotte (2018) developed an optimization problem using the Energy3D software (Energy3D, 2018) as they ask students to optimize an existing building (their school, library, or house). Students analyze the energy performance of the building and its cost and then optimize the energy-efficiency of the building by adding solar panels and changing insulation materials while taking into consideration design constraints. According to Dasgupta et al. (2017), this model allows application of specific science concepts into designed solutions. In another study, Purzer and colleagues also argue that optimization and trade-off tasks allow students to explicitly make connections to scientific core ideas in association with their design solutions (Purzer et al., 2015). Despite limited prior research, this model has high potential in integrating scientific and engineering practices, while reducing time spent on an elaborate ideation process and new design.

\section{Challenges and opportunities}

In summary, the myriad of differences in the instructional models reflect the multi-faceted nature of engineering and the adaptability of the design process in solving different kinds of problems. Yet, despite these differences in how science and engineering are integrated, there are common practices that highlight the pedagogical power of engineering as well as its epistemological pluralism and methodological flexibility. In such classrooms, there will be teachers and students

- communicating about criteria and constraints and clarifying design metrics

- asking questions about associated scientific ideas and existing solutions 
- planning testing and experimentation procedures

- gathering data on design metrics

- analyzing, evaluating, and critiquing data and interpretations

- generating, evaluating, and critiquing new design or re-design decisions

- presenting, justifying, and negotiating with data and scientific backing

The integration of science and engineering in K-12 education presents challenges that need to be framed as opportunities. First, teacher education (in-service teacher professional development and pre-service teacher preparation) needs to be examined with these three frames in mind: pedagogical power, epistemological pluralism, and methodological richness of engineering. For many $\mathrm{K}-12$ teachers, the integration of science and engineering is a new practice (Brophy, Klein, Portsmore, \& Rogers, 2008; Hong, Purzer, \& Cardella, 2011; Yașar, Baker, Robinson-Kurpius, Krause, \& Roberts, 2006). Teacher professional development programs need to differentiate between engineering as a pedagogy versus engineering as a discipline. This distinction would help clarify the belief that engineering simply entails hands-on and building activities, while promoting its core principles as an interdisciplinary field with values pertaining to the betterment of society, care for user needs, and evidencedriven decision-making.

Specifically, research on teacher noticing is critical to promote formative assessment and just-in-time scaffolding (Johnson, Wendell, \& Watkins, 2016; Watkins et al.,
2018). Such research needs to understand teacher classroom practices with an open mind taking into consideration variations and tools which promote evaluating quality, appropriate use of pedagogy, and germane representations of the nature of engineering. Moreover, teacher education should avoid over-emphasis on the steps of the design process and highlight informed design practices of engineers instead, such as importance of problem scoping and prototyping for the puposes of ideation and data gathering as outlined by Crismond and Adams (2012). For further illustration, the design canvas, presented in Fig. 2, helps demonstrate the interrelationships among key design practices, as opposed to the traditional design process cycles. As students use this canvas, they are able to start at any point (understand, ideate, negotiate, or experiment) and can move among the stages fluently.

Second, the development of integrated curricula, assessments, and other instructional resources should be evaluated and designed to reflect the pedagogical power, epistemological pluralism, and methodological flexibility of engineering. The design, development, and evaluation of integrated curricula should also be made with the three perspectives in mind -- differentiating between the pedagogical power of engineering as it helps illustrate concrete uses of abstract scientific concepts, the epistemological pluralism of engineering as design relies on the integration of knowledge and skills from diverse disciplines (natural science, mathematics, social sciences, arts, and humanities), and the methodological flexibility and adaptability of the engineering design process to solve diverse types of

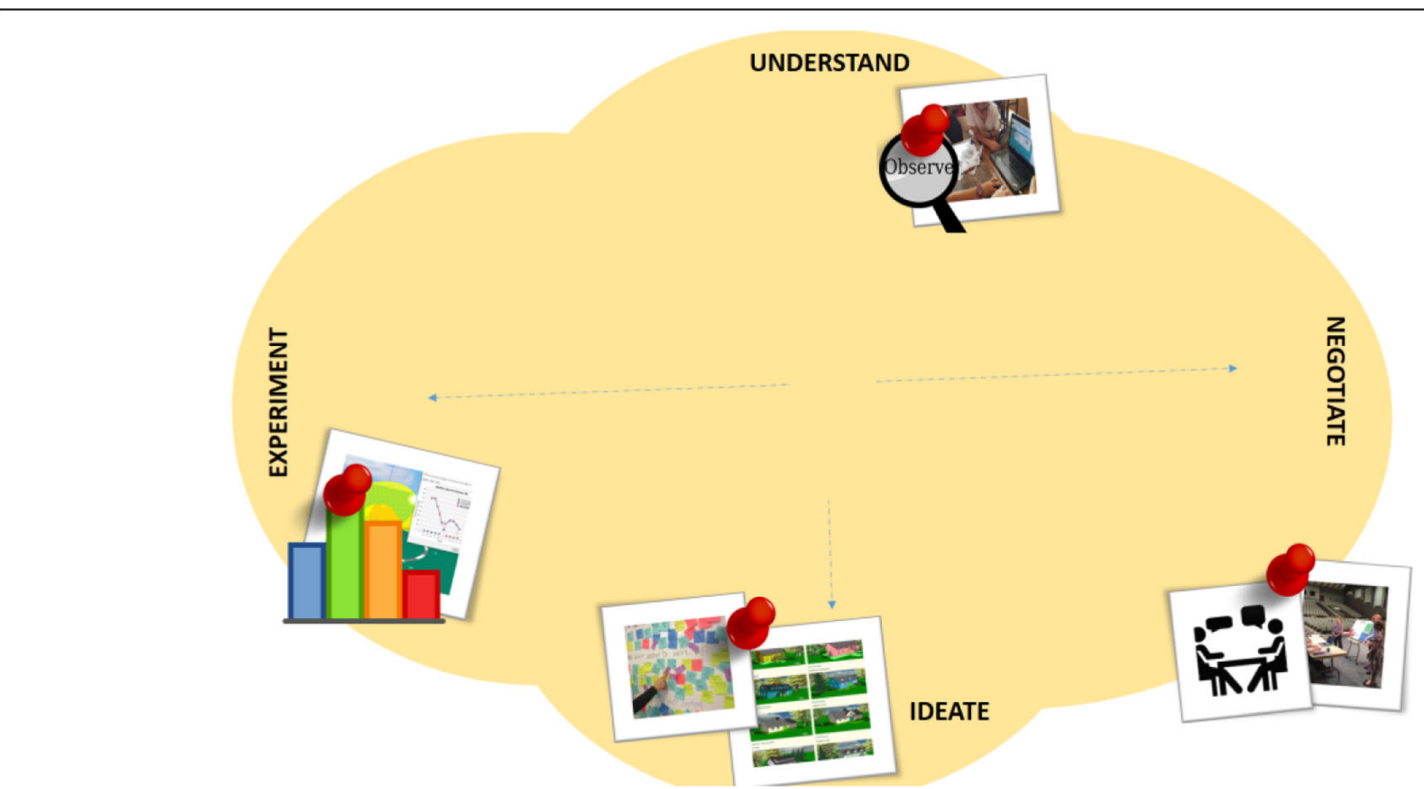

Fig. 2 Design Canvas: An instructional tool that facilitates methodological flexibility 
problems. As we outline in this paper, new design and redesign practices involve emphasis on different cognitive processes (e.g., synthesis vs. analysis) and that curriculum and assessment need to be cognizant of determining appropriate student learning outcomes associated with the specific integration model.

\section{Conclusions and a call for action}

This is a kairotic moment for K-12 education. For the research community, this is the critical moment for change. This call for action to science and engineering educators is translating challenges into opportunities. The success of any new effort partially lies in the challenges associated with the implementation of new practices and our ability to prepare for variations in how the reform ideas are translated into classroom practices. We discussed some of the different models used for the integration of engineering and science in this paper. Undoubtedly, we recommend that the research community builds a research base that recognizes, expands, compares, critiques, and builds on the various approaches we have discussed earlier. There are emerging comparative studies like Goldstein et al. (2018) who found differences between realistic and simulated approaches with each resulting in significant learning outcomes. However, more of such research is needed.

During the early strategies of the reform, it is vital to develop a collective research agenda broad enough to consider both local policy and practices (school districts, schools, and teachers) as well as global policy and practices engaging international collaboration around definitions and research in integrated education. The purpose, reasons and propellers behind the reform effort are beyond the obligations put in front of us. The success of the current state of educational reform is not simply dependent on the local researcher but also on our ability to engage the broader community of global researchers. Well-defined and clearly contextualized research in global forums invites broader international readership, which is necessary to ensure the applicability and transferability of teaching models within diverse education systems across states, school districts, cities, and countries with a globally-tailored research agenda.

In this position paper, we offer the vocabulary necessary to frame future meta-synthesis and meta-analysis studies. We also brainstorm a list of research questions that should be investigated so that in the next 10 years we can create new and transformative knowledge. We argue that by 2030 , the research community should have answered a set of research questions associated with pedagogical, epistemological, and methodological arguments, with several examples presented in Table 4.

We caution that convergence towards one type of practice is problematic. Specifically, we illustrate different models of instruction: user-centered engineering design, design-build-test, engineering experimentation, and optimization. While each model has its pros, cons, and trade-offs, we argue that each model also aligns with the nature of engineering. The divergence in teaching models supports the development of a variety of learning outcomes, while allowing adaptations based on available school resources to broaden the potential for diverse learning outcomes associated with each approach.

The integration of engineering into formal K-12 science education is plausible and necessary for providing an authentic context for useful application and deep understanding of science. Engineering is inherently interdisciplinary and multi-faceted, and hence there is no one type of engineering practice. This paper also offers a common language for science and engineering educators to form a researchbase that recognizes the divergence in teaching models in alignment with the nature of engineering while providing an authentic context for the implementation of scientific concepts. Pedagogical divergence in teaching models supports the development of a variety of learning outcomes, but at the same time accurately represents the nature of engineering. By bringing together science and engineering disciplines as well as science and engineering educators, the $\mathrm{K}-12$ education has much to gain both in enhancing teaching but also advancing research on student learning.

Table 4 Research questions to guide teaching and learning

\begin{tabular}{ll}
\hline Framing & Research questions \\
\hline Pedagogy- & - How do curricula that reflect the integrative nature of engineering help students make connections to science concepts? \\
Epistemology & - Do students who engage in engineering projects develop stronger scientific and technological literacy? And can they \\
& sustain such competencies over time? \\
Pedagogy- & - Do students recognize the design process as a set of strategies that are adaptable to different types of problem solving? \\
Methodology & What are the different affordances associated with different engineering-science integration approaches? For example, do \\
& projects with an optimization model promote deeper understanding of science concepts than those adopting a design- \\
build-test model? & Do teachers have relevant support systems to use different models in the classroom? Do school demographics predict the \\
use of specific teaching methods? & \\
Epistemology- & Do design projects used in classrooms reflect a range of engineering problems (optimization, experimentation, etc) and \\
Methodology & the adaptability of the design process in solving these problems? \\
& Shat barriers and affordances are there in facilitating student designer transitions between concrete design decisions and \\
\end{tabular}




\section{Acknowledgments}

Special thanks to Hadi Banat for his editorial suggestions and critical insights.

\section{Authors' contributions}

SP conceptualized and developed arguments. JPQ analyzed data supporting the arguments. Both authors read and approved the final manuscript.

\section{Funding}

This work is based upon work supported by the National Science Foundation under Grant DUE \#1348547 and DRL \# 1721054. Any opinions, findings, and conclusions or recommendations expressed in this paper, however, are those of the authors and do not necessarily reflect NSF views.

\section{Availability of data and materials}

Not applicable.

\section{Competing interests}

The authors declare that they have no competing interests.

Received: 2 May 2019 Accepted: 17 October 2019

Published online: 28 November 2019

\section{References}

Achieve (2013). The Next Generation Science Standards (NGSS): for states, by states. Retrieved from https://www.nextgenscience.org

Alemdar, M., Lingle, J. A., Wind, S. A., \& Moore, R. A. (2017). Developing an engineering design process assessment using think-aloud interviews. International Journal Engineering Education, 33(1), 441-452.

American Association for the Advancement of Science. (1994). Benchmarks for science literacy. Retrieved from http://www.project2061.org/publications/bsl/ online/index.php

American Institute of Aeronautics and Astronautics. (2019). Design, build, fly. Retrieved from https://www.aiaa.org/dbf

Apedoe, X. S., Reynolds, B., Ellefson, M. R., \& Schunn, C. D. (2008). Bringing engineering design into high school science classrooms: the heating/cooling unit. Journal of Science Education and Technology, 17(5), 454-465. https://doi. org/10.1007/s10956-008-9114-6.

Apedoe, X. S., \& Schunn, C. D. (2013). Strategies for success: uncovering what makes students successful in design and learning. Instructional Science, 41(4), 773-791. https://doi.org/10.1007/s11251-012-9251-4

Ballyns, J., Doran, R., Archer, S., \& Bonassar, L. (2011). An introduction to tissue engineering using hydrogels. Science Scope, 35(1), 50-56 Retrieved from http://www.jstor.org/stable/43183104.

Batliner, M., Boës, S., Heinis, S., \& Meboldt, M. (2018). Testing methodology for engineering design education. In International conference on engineering and product design education. London: Dyson School of Design Engineering, Imperial College.

Berland, L. K. (2013). Designing for STEM integration. Journal of Pre-College Engineering Education, 3(1), 22-31. https://doi.org/10.7771/2157-9288.1078.

Brophy, S., Klein, S., Portsmore, M., \& Rogers, C. (2008). Advancing engineering education in P-12 classrooms. Journal of Engineering Education, 97(3), 369387. https://doi.org/10.1002/j.2168-9830.2008.tb00985.x.

Cajas, F. (2001). The science/technology interaction: implications for science literacy. Journal of Research in Science Teaching, 38(7), 715-729. https://doi. org/10.1002/tea.1028.

Cantrell, P., Pekcan, G., Itani, A., \& Velasquez-Bryant, N. (2006). The effects of engineering modules on student learning in middle school science classrooms. Journal of Engineering Education, 95(4), 301-309. https://doi.org/ 10.1002/j.2168-9830.2006.tb00905.x.

Capobianco, B. M., \& Rupp, M. (2014). STEM teachers' planned and enacted attempts at implementing engineering design-based instruction. School Science and Mathematics, 114(6), 258-270. https://doi.org/10.1111/ssm.12078.

Carr, R. L., Bennett IV, L. D., \& Strobel, J. (2012). Engineering in the K-12 STEM standards of the 50 US states: an analysis of presence and extent. Journal of Engineering Education, 101(3), 539-564. https://doi.org/10.1002/j.2168-9830. 2012.tb00061.x.

Chao, J., Xie, C., Nourian, S., Chen, G., Bailey, S., Goldstein, M. H., Tutwiler, M. S. (2017). Bridging the design-science gap with tools: science learning and design behaviors in a simulated environment for engineering design. Journal of Research in Science Teaching, 54(8), 1049-1096. https://doi.org/10.1002/tea.21398.
Chinn, C. A., \& Malhotra, B. A. (2002). Epistemologically authentic inquiry in schools: a theoretical framework for evaluating inquiry tasks. Science Education, 86(2), 175-218. https://doi.org/10.1002/sce.10001.

Cook, K. L., Bush, S. B., \& Cox, R. (2015). Engineering encounters: creating a prosthetic hand. Science \& Children, 53(4), 80-86 Retrieved from http://www. jstor.org/stable/43692062

Crismond, D. (2001). Learning and using science ideas when doing investigateand-redesign tasks: a study of naive, novice, and expert designers doing constrained and scaffolded design work. Journal of Research in Science Teaching, 38(7), 791-820. https://doi.org/10.1002/tea.1032.

Crismond, D. P., \& Adams, R. S. (2012). The informed design teaching and learning matrix. Journal of Engineering Education, 101(4), 738-797. https://doi. org/10.1002/j.2168-9830.2012.tb01127.x.

Cunningham, C. M., \& Kelly, G. J. (2017). Epistemic practices of engineering for education. Science Education, 101(3), 486-505. https://doi.org/10.1002/sce.21271.

Czerniak, C. M., Weber Jr., W. B., Sandmann, A., \& Ahern, J. (1999). A literature review of science and mathematics integration. School Science and Mathematics, 99(8), 421-430. https://doi.org/10.1111/j.1949-8594.1999. tb17504.x.

Dasgupta, C., Sanzenbacher, B., Siegel, J., Mcbeath, D., \& Moher, T. (2017). Call the plumber. Science Scope, 40(5), 50 Retrieved from http:/www.jstor.org/ stable/26389038.

Daugherty, J. L., \& Custer, R. L. (2012). Secondary level engineering professional development: content, pedagogy, and challenges. International Journal of Technology and Design Education, 22(1), 51-64. https://doi.org/10.1007/ s10798-010-9136-2.

Dixon, J. R. (1966). Design engineering: Inventiveness, analysis, and decision making. New York: McGraw-Hill.

Dyer, J. H., Gregersen, H. B., \& Christensen, C. (2008). Entrepreneur behaviors, opportunity recognition, and the origins of innovative ventures. Strategic Entrepreneurship Journal, 2(4), 317-338. https://doi.org/10.1002/sej.59.

Energy3D [Computer software]. (2018). Learning to build a sustainable world. Retrieved from http://energy.concord.org/energy3d/

Ewalt, K., Dortch, B., \& Russell, V. (2015). See-less seagulls: planning for an interdisciplinary STEM unit. Science Scope, 39(2), 18 Retrieved from http:// www.jstor.org/stable/43691334.

Figueiredo, A. D. d. (2008). Toward an epistemology of engineering. In 2008 Workshop on Philosophy and Engineering. London: The Royal Academy of Engineering Available at SSRN: https://ssrn.com/abstract=1314224.

Fortus, D., Dershimer, R. C., Krajcik, J., Marx, R. W., \& Mamlok-Naaman, R. (2004). Design-based science and student learning. Journal of Research in Science Teaching, 41(10), 1081-1110. https://doi.org/10.1002/tea.20040.

Goldstein, M. G., Loy, B., \& Purzer, Ş. (2017). Designing a sustainable neighborhood: an interdisciplinary project-based energy and engineering unit in the seventh-grade classroom. Science Scope, 41(1), 32-41. https://doi. org/10.2505/4/ss17_041_01_32.

Goldstein, M. H., Omar, S. A., Purzer, S., \& Adams, R. (2018). Comparing two approaches to engineering design in the seventh grade science classroom. International Journal Engineering Education, 6(4), 381-397. https://doi.org/10. 18404/ijemst.440340.

Hamilton, E., Lesh, R., Lester, F., \& Brilleslyper, M. (2008). Model-Eliciting Activities (MEAs) as a bridge between engineering education research and mathematics education research. Advances in Engineering Education, 1(2), 1-25.

Hoffmann, K. (2013). Bringing earthquake engineering to your hometown. Science Scope, 37(4), 45-51 Retrieved from http://www.jstor.org/stable/43691131.

Hong, T., Purzer, Ş.. \& Cardella, M. (2011). A re-evaluation of the design, engineering and technology (DET) instrument. Journal of Engineering Education, 100(4), 800818. https://doi.org/10.1002/j.2168-9830.2011.tb00037.x.

Hsu, M.-C., Cardella, M. E., \& Purzer, S. (2012). Elementary students' engineering design process knowledge: instrument development and pilot test. In Proceedings of the 117th American Society for Engineering Education Annual Conference and Exposition, Louisville, KY.

International Technology Education Association (2007). Standards for technological literacy: content for the study of technology. Reston: ITEEA.

Johnson, A. W., Wendell, K. B., \& Watkins, J. (2016). Dimensions of experienced responsive teaching in engineering. In Proceedings of the 123th American Society for Engineering Education Annual Conference and Exposition, New Orleans, LA.

Karahan, E., Guzey, S. S., \& Moore, T. (2014). Saving pelicans. Science Scope, 38(3), 28 Retrieved from http://www.jstor.org/stable/43184313.

Kolodner, J. L. (2002). Facilitating the learning of design practices: lessons learned from an inquiry into science education. Journal of Industrial Teacher 
Education, 39(3), 9-40 Retrieve from: https://scholar.lib.vt.edu/ejournals/JTE/ v39n3/kolodner.html.

Kolodner, J. L., Camp, P. J., Crismond, D., Fasse, B., Gray, J., Holbrook, J., Ryan, M. (2003). Problem-based learning meets case-based reasoning in the middleschool science classroom: putting learning by design $(\mathrm{tm})$ into practice. The Journal of the Learning Sciences, 12(4), 495-547. https://doi.org/10.1207/ S15327809JLS1204_2.

Kroes, P. (2009a). Foundational issues of engineering design. In D. M. Gabbay, P. Thagard, \& J. Woods (Eds.), Philosophy of technology and engineering sciences, (pp. 513-541). The Netherlands: North Holland Elsevier.

Kroes, P. (2009b). Introduction to part III. In D. M. Gabbay, P. Thagard, \& J. Woods (Eds.), Philosophy of technology and engineering sciences, (pp. 405-408). The Netherlands: North Holland-Elsevier.

Lewis, T. (2006). Design and inquiry: bases for an accommodation between science and technology education in the curriculum? Journal of Research in Science Teaching, 43(3), 255-281. https://doi.org/10.1002/tea.20111.

Massachusetts Department of Education (2001). Massachusetts science and technology/ engineering curriculum framework. Malden: Massachusetts Department of Education.

Massachusetts Department of Elementary and Secondary Education (2016). Massachusetts science and technology/engineering curriculum framework. Malden: Massachusetts Department of Education Retrieved from http://www. doe.mass.edu/frameworks/scitech/2016-04.pdf.

Mathis, C. A., Siverling, E. A., Glancy, A. W., \& Moore, T. J. (2017). Teachers' incorporation of argumentation to support engineering learning in STEM integration curricula. Journal of Pre-College Engineering Education Research (JPEER), 7(1), 76-89. https://doi.org/10.7771/2157-9288.1163.

Mentzer, N., Becker, K., \& Sutton, M. (2015). Engineering design thinking: High school students' performance and knowledge. Journal of Engineering Education, 104(4), 417-432. https://doi.org/10.1002/jee.20105.

Mitchan, K., \& Schatzberg, E. (2009). Defining technology and the engineering science. In A. Meijers (Ed.), Philosophy of technology engineering science, (pp. 27-63). Oxford: North-Holland Elsevier. https://doi.org/10.1016/B978-0-44451667-1.50006-9.

Moore, T.J., Tank, K.M., Gajdzik, E., Sanger, M.T., Rynearson, A.M., Babjide, B. (2015). Picture STEM: designing hamster habitats. Retrieved from http://picturestem. org/picturestem-units/first-grade-hamsters

Moore, T. J., Tank, K. M., Glancy, A. W., \& Kersten, J. A. (2015). NGSS and the landscape of engineering in K-12 state science standards. Journal of Research in Science Teaching, 52(3), 296-318. https://doi.org/10.1002/tea.21199.

Museum of Science (2019). Engineering is elementary [Curriculum]. Boston, MA. Retrieved from https://www.eie.org/eie-curriculum

Nathan, M. J., Atwood, A. K., Prevost, A., Phelps, L. A., \& Tran, N. A. (2011). How professional development in Project Lead the Way changes high school STEM teachers' beliefs about engineering education. Journal of Pre-College Engineering Education Research (J-PEER), 1(1), 3. https://doi.org/10.7771/2157-9288.1027.

National Academy of Engineering (2009). Engineering in K-12 education: Understanding the status and improving the prospects. Washington, DC: National Academies Press.

National Academy of Engineering (2010). Standards for K-12 engineering education? Washington, DC: National Academies Press.

National Assessment of Educational Progress. (2014). 2014 Technology \& Engineering Literacy (TEL) Overall Results. Retrieved from https://www. nationsreportcard.gov/tel_2014/\#results/overall

National Research Council (1996). National science education standards. Washington, DC: National Academies Press.

National Research Council (2012). A framework for K-12 science education: practices, crosscutting themes, and core ideas. Washington, DC: National Academies Press.

OECD (2014). PISA 2012 results (volume V): creative problem solving: students' skills in tackling real-life problems. Paris: OECD Publishing Retrieved from http:// www.oecd.org/pisa/keyfindings/pisa-2012-results-volume-v.htm.

OECD (2017). PISA 2015 results (volume V): collaborative problem solving. Paris: OECD Publishing Retrieved from https://doi.org/10.1787/9789264285521-en.

Pang, J., \& Good, R. (2000). A review of the integration of science and mathematics: implications for further research. School Science and Mathematics, 100(2), 73-82. https://doi.org/10.1111/j.1949-8594.2000.tb17239.x.

Peters-Burton, E. E., \& Johnson, T. (2018). Cross-case analysis of engineering education experiences in inclusive stem-focused high schools in the United States. International Journal of Education in Mathematics Science and Technology, 6(4), 320-342. https://doi.org/10.18404/ijemst.440335.
Purzer, S. (2018). How different are engineering design projects?: An analysis of middle school lessons and units. Denmark: European Society of Engineering Education (SEFI), Copenhagen Retrieved from https://www.sefi.be/wpcontent/uploads/2018/10/SEFI-Proceedings-2-October-2018.pdf.

Purzer, Ş., Goldstein, M. H., Adams, R. S., Xie, C., \& Nourian, S. (2015). An exploratory study of informed engineering design behaviors associated with scientific explanations. International Journal of STEM Education, 2(1), 9.

Purzer, S., Moore, T., Baker, D., Berland, L. (2014). Supporting the implementation of the Next Generation Science Standards (NGSS) through research: engineering. Retrieved from https://www.narst.org/ ngsspapers/engineering.cfm

Purzer, S., \& Quintana-Cifuentes, J. G. (2019, April). Six ways of integrating science and engineering: What do students learn from each? Paper presented at the Annual Conference of NARST, Baltimore, MD.

Radcliffe, D. (2015). A tale of two STEMS. Prism, 25(4), 52 Retrieved from http:// www.asee-prism.org/last-word-dec-3/.

Radder, H. (2009). Science, technology and the science-technology relationship. In A. Meijers (Ed.), Philosophy of technology and engineering sciences, (pp. 6591). Amsterdam, The Netherlands: North-Holland.

Roehrig, G. H., Moore, T. J., Wang, H.H., \& Park, M. S. (2012). Is adding the E enough? Investigating the impact of K-12 engineering standards on the implementation of STEM integration. School Science \& Mathematics, 112(1), 31-44. https://doi.org/10.1111/j.1949-8594.2011.00112.x.

Silk, E. M., Schunn, C. D., \& Cary, M. S. (2009). The impact of an engineering design curriculum on science reasoning in an urban setting. Journal of Science Education and Technology, 18(3), 209-223. https://doi.org/10.1007/ s10956-009-9144-8.

Sneider, C., \& Purzer, S. (2014). The rising profile of STEM literacy through national standards and assessments. In Ş. Purzer, J. Strobel, \& M. Cardella (Eds.), Engineering in pre-college settings: Synthesizing research, policy, and practices, (pp. 3-19). West Lafayette: Purdue University Press.

Svarovsky, G. N. (2011). Exploring complex engineering learning over time with epistemic network analysis. Journal of Pre-College Engineering Education Research (J-PEER), 1(2), 4. https://doi.org/10.5703/1288284314638.

Watkins, J., McCormick, M., Wendell, K. B., Spencer, K., Milto, E., Portsmore, M., \& Hammer, D. (2018). Data-based conjectures for supporting responsive teaching in engineering design with elementary teachers. Science Education, 102(3), 548-570. https://doi.org/10.1002/sce.21334.

Wendell, B. K., \& Rogers, C. (2013). Engineering design-based science, science content performance, and science attitudes in elementary school. Journal of Engineering Education, 102(4), 513-540. https://doi.org/10.1002/jee.20026.

Xie, C., Schimpf, C., Chao, J., Nourian, S., \& Massicotte, J. (2018). Learning and teaching engineering design through modeling and simulation on a CAD platform. Computer Applications in Engineering Education, 26(4), 824-840. https://doi.org/10.1002/cae.21920.

Yaşar, Ş., Baker, D., Robinson-Kurpius, S., Krause, S., \& Roberts, C. (2006). Development of a survey to assess K-12 teachers' perceptions of engineers and familiarity with teaching design, engineering, and technology. Journal of Engineering Education, 95(3), 205-216. https://doi.org/10.1002/j.2168-9830. 2006.tb00893x

\section{Publisher's Note}

Springer Nature remains neutral with regard to jurisdictional claims in published maps and institutional affiliations. 